\title{
Oral health-related quality of life among pediatric liver transplant candidates
}

\author{
Evelyn Alvarez VIDIGAL (a) \\ Jenny ABANTO(a) (iD \\ Ana Estela HADDAD(a) iD \\ Gilda PORTA(b) iD \\ Fábio Abreu ALVES(c) iD \\ Marcelo BÖNECKER ${ }^{(a)}$ iD \\ (a) Universidade de São Paulo - USP, School of \\ Dentistry, Department of Pediatric Dentistry \\ and Orthodontics, São Paulo, SP, Brazil. \\ (b)A. C. Camargo Cancer Center, Department \\ of Liver Transplantation, São Paulo, SP, Brazil. \\ (c)A. C. Camargo Cancer Center, Stomatology \\ Department, São Paulo, SP, Brazil.
}

Declaration of Interests: The authors certify that they have no commercial or associative interest that represents a conflict of interest in connection with the manuscript.

\section{Corresponding Author:}

Evelyn A. Vidigal

E-mail: evelyn_vidigal@hotmail.com

hitps://doi.org/10.1590/1807-3107bor-2020.vol34.0100

Submitted: March 9, 2020

Accepted for publication: June 16. 2020

Last revision: July 6, 2020
Abstract: To assess the impact of oral conditions on the oral health-related quality of life (OHRQoL) of pediatric liver transplant candidates. This cross-sectional study included 60 children aged 13 to 48 months who were liver transplant candidates that attended the AC Camargo Cancer Center, São Paulo, Brazil. On the day of oral examinations, the children's mothers were invited to answer two questionnaires; one related to children's OHRQoL using the B-ECOHIS and another related to socioeconomic/demographic characteristics. Thereafter, a single, adequately trained dentist carried out children's oral examinations for gingival inflammation (Silness-Löe index), dental plaque (Green-Vermillion Simplified index), dental caries (dmft index), developmental defects of enamel (DDE index), tooth discoloration, oral mucosal/lip alterations. The data collected also included socioeconomic/demographic characteristics and liver disease. The adjusted Poisson regression model was used to associate children's socioeconomic/demographic characteristics and clinical conditions to the outcome. The adjusted regression model showed that children with untreated caries lesions $(\mathrm{RR}=3.35, \mathrm{p}<0.0001)$ and tooth discoloration $(\mathrm{RR}=1.74, \mathrm{p}=0.04)$ had poorer total B-ECOHIS scores. Dental discoloration and untreated caries lesions had a negative impact on the OHRQoL in pediatric liver transplant candidates.

Keywords: Child, Preschool; Liver Diseases; Quality of Life; Oral Health.

\section{Introduction}

Chronic liver diseases, which imply long-standing irreversible changes in hepatic structure, are considered a common cause of morbidity and mortality in children. ${ }^{1}$ One of these diseases, biliary atresia, is a major issue in pediatrics since it is the main indication for liver transplantation in children. ${ }^{2}$ There is a paucity of literature on the oral conditions of children with liver disease. Most of the studies related to this topic are case reports that have described the presence of certain oral conditions, which include gingival inflammation, higher susceptibility to dental caries, tooth discoloration caused by bilirubin, and developmental defects of enamel (DDE). ${ }^{3,4,5,6,7}$

Pediatric liver transplant candidates could present with poorer general health due to the underlying disease. In this context, the oral health 
conditions in children awaiting liver transplant also could affect their daily activities. Considering that parents are responsible for these children's health care, parents' perception of how the quality of life of their children could be affected by oral conditions is an important topic. Oral health-related quality of life (OHRQoL) is a multidimensional concept related to the impact of adverse oral conditions on an individual's daily functioning, well-being, and quality of life. ${ }^{8,9}$

Diverse cross-sectional studies have been conducted and they have demonstrated that oral problems such as dental caries and traumatic dental injuries have a negative impact on preschool children's OHRQoL. 10,11,12 Nevertheless, a few studies have evaluated the OHRQoL in children with systemic diseases. ${ }^{13,14,15}$ To the best of our knowledge, there are no studies that have assessed the impact of oral health conditions on the OHRQoL of children awaiting liver transplantation. Thus, the purpose of this study was to assess the impact of oral health conditions on the OHRQoL in children who were candidates for liver transplantation.

\section{Methodology}

\section{Ethical approval}

The study was approved by both the Ethical Committees of the Dental School, University of São Paulo, and AC Camargo Cancer Center; and registered under protocol 626.286 and 1897/14 respectively, in compliance with the Brazilian National Health Council Resolution number 466/12. All parents were informed about the objectives of the study and the procedures. Written informed consent was obtained before the study from all the children's parents.

\section{Study population and data collection}

This cross-sectional study was conducted on a convenience sample of 60 children attending the AC Camargo Cancer Center, São Paulo, Brazil; which is a reference center for liver transplantation. The participants were recruited over 17 months. All children who were awaiting liver transplantation during this period were included in the study. The study sample was therefore composed of children aged 13 to 48 months, who were liver transplant candidates. Children who had already undergone liver transplantation were excluded. On the day of the dental appointment, one of the parents was invited to fill two questionnaires: one related to children's OHRQoL using the Brazilian version of the ECOHIS (B-ECOHIS) ${ }^{16,17,18}$ and another related to socioeconomic/demographic conditions and liver disease diagnoses. These data were collected before the oral examination by a single examiner who was a dentist trained in the reading and intonation of each questionnaire's questions. Children's oral examination for gingival inflammation, ${ }^{19}$ dental plaque ${ }^{20}$ dental caries, ${ }^{21} \mathrm{DDE},{ }^{22}$ tooth discoloration, and oral mucosal/lip alterations ${ }^{21}$ was conducted by the same dentist, who had undergone a specific training exercise that consists of a theoretical and a clinical phase. In this process, a total of 10 children, who were not included in the study, were examined twice by the dentist with an interval of 7 days between the examinations. The training exercise was carried out by a benchmark dental examiner. As a result of the calibration process, the kappa value for intra-examiner reliability was greater than 0.8 for all oral clinical conditions evaluated.

\section{Socioeconomic/demographic and liver disease diagnosis questionnaire}

The questionnaires with questions on socioeconomic and demographic conditions were filled by the children's parents. It included data such children's gender, age (months), family structure (children live with both parents or not), number of siblings (none, 1 or 2, 3 or more), parents' schooling ( $\leq 8$ years or $>8$ years) and monthly household income in Brazilian real (BRL). The exchange rate as of when the data were gathered was as follows: $1.00 \mathrm{USD}=4.40 \mathrm{BRL}$. Liver disease diagnoses were obtained by asking the parents about their children's underlying liver disease such as biliary atresia, familial cholestasis, fulminant hepatitis, primary sclerosing cholangitis, cryptogenic cirrhosis, neonatal hepatitis, alpha-1-anti-trypsin deficiency, choledochal cyst, autoimmune hepatitis, congenital hepatic fibrosis, or other liver diseases. 


\section{Children's OHRQoL data}

Children's parents were asked to answer the B-ECOHIS to assess the impact of the children's oral conditions on the OHRQoL. The B-ECOHIS measures the impact of oral problems on the quality of life in children below the age of five and their parents. ${ }^{16,17,18}$ This quality of life questionnaire evaluates the perceptions of parents on the OHRQoL of their children and contains 13 items distributed in the Child Impact Section and the Family Impact Section. The Child Impact Section has four domains: symptoms (1 question); function (4 questions); psychological (2 questions); and selfimage/social interaction (2 questions). The Family Impact Section has two domains: parental distress (2 questions) and family function (2 questions). The response categories for the B-ECOHIS were coded as follows: 0 = never; 1 = hardly ever; $2=$ occasionally; $3=$ often; $4=$ very often and $5=$ don't know. The total B-ECOHIS score ranges from 0 to 52, with higher scores indicating greater oral health impact and poorer OHRQoL.

\section{Children's oral examination}

Children who receive medical treatment at the AC Camargo Cancer Center are examined and receive dental treatment, when necessary, before liver transplantation. In this study, oral evaluations were performed in the Dental Department of the AC Camargo Cancer Center. The oral examinations for gingival inflammation, dental plaque, dental caries, DDE, tooth discoloration, oral mucosal/lip alterations were performed in a dental unit with an operating light, a three-in-one syringe for drying the teeth, ball-ended probe, mouth mirrors, and a disposable tongue depressor. Gingival inflammation and dental plaque were assessed using the Silness-Löe Gingival Inflammation Index ${ }^{19}$ and the Green-Vermillion Oral Hygiene Simplified Index ${ }^{20}$ respectively.

Dental caries was assessed using the WHO criteria $^{21}$ and calculated using the $\mathrm{dmft}$ index. Untreated dental caries was considered in this study due to its association with the preschool children's quality of $\operatorname{life}^{23}$ and categorized for statistical purposes. The presence of DDE was evaluated according to the DDE inde ${ }^{22}$ by diagnosing and classifying changes in the dental enamel. These alterations were recorded as normal, demarcated or diffuse opacities, hypoplasia, demarcated and diffuse opacities, demarcated opacities and hypoplasia, diffuse opacities and hypoplasia, and other defects. The distribution on the enamel surface of these alterations was also recorded as follows: absent, $<1 / 3$ enamel surface, and $1 / 3 \leq$ enamel surface $<2 / 3$.

It is known that the primary teeth usually look whiter than the permanent teeth ${ }^{24}$ and that green stains are a characteristic teeth discoloration of individuals with liver diseases caused by hyperbilirubinemia. ${ }^{7}$ In this study, tooth discoloration was measured by recording the presence or absence of color alterations (such as green or yellow/green) in the dental structure. Thus, this variable was dichotomized (for statistical purposes) as presence or absence of tooth discoloration. Oral mucosal and lip abnormalities were also evaluated by diagnosing the presence or absence of any alteration and the oral examination was conducted according to the WHO criteria. ${ }^{21}$ All children's oral examination abovementioned were performed by using behavioral management techniques since they were young children.

\section{Statistical analysis}

Data analyzes were performed using STATA software 9.0 (Stata Corp., College Station, TX, USA). Initially, descriptive analyzes were performed and frequency distributions were produced for socioeconomic, demographic, and oral clinical conditions of the sample. Descriptive analyzes were performed to assess measures of central tendency (means, standard deviations, and ranges) of individual and total domain scores of the B-ECOHIS. The Poisson regression analysis with robust variance was performed to correlate individual domains and total B-ECOHIS scores with oral clinical conditions and socioeconomic/demographic characteristics of the sample. The unadjusted Poisson regression analysis was performed to select variables with p-values $\leq$ 0.20 to enter the model. Explanatory variables were tested in the adjusted model and retained only if they had p-values $\leq 0.05$. The outcome OHRQoL was analyzed as account outcome, hence Rate Ratio (RR) and 95\% confidence intervals were calculated. 


\section{Results}

The sample power was calculated in the OpenEpi Online program (www.openepi.com) using means and standard deviations for total ECOHIS scores among children without and with untreated dental caries (mean $\pm \mathrm{SD}=4.024 \pm 4.269$ and $18.052 \pm 6.645$ respectively), as well as among children without and with dental pigmentation (mean \pm $\mathrm{SD}=3.444 \pm 4.610$ and $12.575 \pm 8.455$ respectively). Both variables remained in the final model. The results showed that at a 95\% confidence interval, the G Power was $100 \%$.

All the questionnaires were filled by children's mothers (positive response rate of $100 \%$ ). Socioeconomic/demographic characteristics and liver disease diagnoses are presented in Table 1. The sample consisted of 60 children with a mean age of $19 \pm 7.44$ months. Most of the children evaluated lived with both parents (75\%) and 60\% of them had one or two siblings. A majority of the children's parents had less than 8 years of schooling. Moreover, the main underlying liver disease was biliary atresia (68.3\%).

Regarding the oral health conditions of the 60 preschool children examined, the mean $\mathrm{dmft}$ index was $0.65 \pm 1.13$ and untreated caries lesions were present in $31.7 \%$ of the children. A total of $45 \%$ of the children had tooth discoloration while $18.3 \%$ and $6.7 \%$ had opacities and hypoplasia respectively. Moreover, the presence of dried lips (18.3\%), swollen lips (16.7\%), and fissured lips (18.3\%) was also observed (Table 2).

All children's mothers interviewed in this study filled the B-ECOHIS questionnaire. All questions were answered and there was no such answer as "I don't know". In the unadjusted analysis, a significant association was found between some independent variables and total scores of the B-ECOHIS ( $p<0.05)$. Total B-ECOHIS scores showed significant associations with children aged 13 to 24 and 25 to 48 months, father's schooling higher than 8 years, untreated caries lesions, moderate and severe gingival inflammation, moderate and poor oral hygiene, presence of tooth discoloration, and presence of enamel defects on $\geq 1 / 3$ of tooth surface area $(\mathrm{p}<0.05)($ Table 3$)$.
The adjusted regression model associated with the total scores of the B-ECOHIS showed that untreated dental caries lesions proved to have a negative impact

Table 1. Socioeconomic/demographic characteristics and liver disease diagnoses of pediatric liver transplant candidates $(\mathrm{n}=60)$.

\begin{tabular}{|c|c|}
\hline Variable & $n(\%)$ \\
\hline \multicolumn{2}{|l|}{ Gender } \\
\hline Girls & $31(51.7)$ \\
\hline Boys & $29(48.3)$ \\
\hline \multicolumn{2}{|l|}{ Age (months) } \\
\hline$\leq 12$ & $10(16.7)$ \\
\hline $13-24$ & $37(61.7)$ \\
\hline $25-48$ & $13(21.7)$ \\
\hline \multicolumn{2}{|l|}{ Responsible person } \\
\hline Mother & $60(100)$ \\
\hline Father & $0(0)$ \\
\hline \multicolumn{2}{|l|}{ Lives with } \\
\hline Both parents & $45(75)$ \\
\hline Only mother & $15(25)$ \\
\hline \multicolumn{2}{|l|}{ Siblings } \\
\hline No siblings & $5(8.3)$ \\
\hline 1 or 2 siblings & $36(60)$ \\
\hline 3 or more & $19(31.7)$ \\
\hline \multicolumn{2}{|l|}{ Mother's schooling } \\
\hline$\leq 8$ years & $33(55)$ \\
\hline$>8$ years & $27(45)$ \\
\hline \multicolumn{2}{|l|}{ Father's schooling } \\
\hline$\leq 8$ years & $32(53.3)$ \\
\hline$>8$ years & $28(46.7)$ \\
\hline \multicolumn{2}{|l|}{ Household income* } \\
\hline Mean \pm SD monthly income & $1113.53 \pm 509.027$ \\
\hline \multicolumn{2}{|l|}{ Liver disease } \\
\hline Biliary atresia & $41(68.3)$ \\
\hline Familial cholestasis & $13(21.7)$ \\
\hline Fulminant hepatitis & $3(5)$ \\
\hline Primary sclerosing cholangitis & $1(1.7)$ \\
\hline Cryptogenic cirrhosis & $1(1.7)$ \\
\hline Neonatal hepatitis & $1(1.7)$ \\
\hline
\end{tabular}

${ }^{*}$ Household monthly income in Brazilian real (BRL) which corresponds to approximately $1.00 \mathrm{USD}=4.40 \mathrm{BRL}$ when the data were gathered 
Table 2. Oral health conditions of pediatric liver transplant candidates $(\mathrm{n}=60)$.

\begin{tabular}{|c|c|}
\hline Oral conditions & $\mathrm{N}(\%)$ \\
\hline \multicolumn{2}{|l|}{ Untreated dental caries lesions } \\
\hline Yes & $19(31.7)$ \\
\hline No & $41(68.3)$ \\
\hline \multicolumn{2}{|l|}{ GI } \\
\hline Mild & $40(66.7)$ \\
\hline Moderate & $12(20)$ \\
\hline Severe & $8(13.3)$ \\
\hline \multicolumn{2}{|l|}{$\mathrm{OHI}-\mathrm{S}$} \\
\hline Excellent & $12(20)$ \\
\hline Good & $22(36.7)$ \\
\hline Moderate & $13(21.7)$ \\
\hline Poor & $13(21.7)$ \\
\hline \multicolumn{2}{|c|}{ Tooth discoloration (hyperbilirubinemia) } \\
\hline Yes & $33(45)$ \\
\hline No & $27(55)$ \\
\hline \multicolumn{2}{|l|}{ DDE Index } \\
\hline Normal & $45(75)$ \\
\hline Demarcated/diffuse opacities & $11(18.3)$ \\
\hline Hypoplasia & $4(6.7)$ \\
\hline \multicolumn{2}{|l|}{ DDE Index - extension } \\
\hline Absence & $45(75)$ \\
\hline$<1 / 3$ & $13(21.7)$ \\
\hline$\geq 1 / 3<2 / 3$ & $2(3.3)$ \\
\hline \multicolumn{2}{|l|}{ Dried lips } \\
\hline Yes & $11(18.3)$ \\
\hline No & $49(81.7)$ \\
\hline \multicolumn{2}{|l|}{ Swollen lips } \\
\hline Yes & $10(16.7)$ \\
\hline No & $50(83.3)$ \\
\hline \multicolumn{2}{|l|}{ Fissured lips } \\
\hline Yes & $11(18.3)$ \\
\hline No & $49(81.7)$ \\
\hline
\end{tabular}

GI: Gingival Index; OHI-S: Simplified Oral Hygiene Index; DDE: Developmental defects of enamel.

on total B-ECOHIS scores $(\mathrm{RR}=3.35 ; \mathrm{p}<0.0001)$. Moreover, the presence of tooth discoloration demonstrated a negative impact on total B-ECOHIS scores $(R R=1.74 ; p=0.04)($ Table 3$)$.

\section{Discussion}

The majority of the studies regarding oral conditions in children with liver diseases are case reports. ${ }^{3,4,5,6,7}$ To the best of our knowledge, this is the first cross-sectional study to assess the impact of oral health conditions on the OHRQoL of children candidates for liver transplantation.

A high prevalence of dental caries in children with liver disease has been reported. ${ }^{4,5}$ However, in our study, a lower prevalence of untreated dental caries was observed (31.7\%), which was also lower than that observed at the last national Brazilian epidemiological survey for 5 -year-old children (53.4\%). ${ }^{25}$ Nevertheless, untreated caries lesions had a negative impact on the children's OHRQoL in this study.

In the present research, dental caries was analyzed considering the untreated caries lesions since this condition reflects the current state of the disease and not only past experiences. ${ }^{26}$ Thus, children who had untreated caries lesions could manifest pain and discomfort which could affect their daily lives. This is in accordance with previous studies that demonstrated that untreated dental caries has a negative impact on the OHRQoL of preschool children. ${ }^{27,28}$ Although these studies were conducted in preschool children free of systemic diseases, other studies in specific populations, such as children with cerebral palsy and HIV+ have shown that dental caries had a negative impact on children's OHRQoL. ${ }^{13,15}$ Therefore, dental caries appears to be a disease which has a negative impact on the OHRQoL of all individuals with or without systemic diseases.

Biliary atresia is the most common cause of pediatric end-stage liver disease and the leading indication for pediatric liver transplantation. ${ }^{29}$ Hyperbilirubinemia causes green-stained teeth ${ }^{6,7,24}$ which is a common feature observed in children with liver disease $\mathrm{e}^{3,4,5,6}$ mainly in those diagnosed with biliary atresia. ${ }^{3,4,6}$ In this study, most of the children were diagnosed with biliary atresia $(68.3 \%)$, and the presence of tooth discoloration (45\%) was observed, which ranged from yellow to yellow/green shades. Notwithstanding, most of the children showed yellowcolored teeth, and only a few cases of yellow/greenstained teeth were observed. 
Oral health-related quality of life among pediatric liver transplant candidates

Table 3. Unadjusted and adjusted regression model of the demographic characteristics and oral health conditions variables associated with total scores of the Brazilian Early Childhood Oral Health Impact Scale (B-ECOHIS).

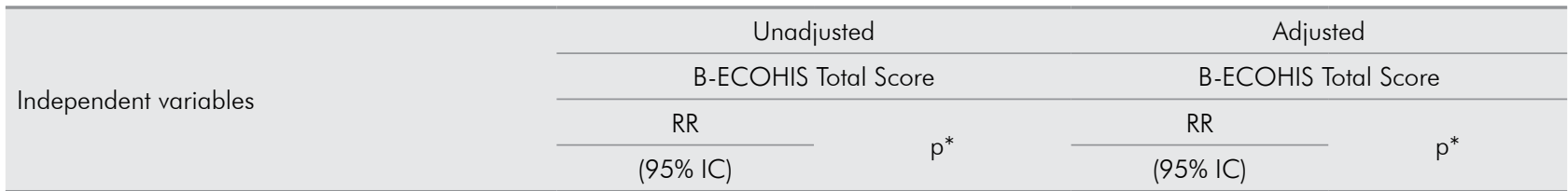

Demographic conditions

Age (months)

$\leq 12$

1

$13-24$

$2.31(1.12-4.78)$

0.02

$\dagger$

25-48

6.59 (3.30-13.17)

$<0.0001$

Gender

Boys

1

Girls

$1.43(0.86-2.40)$

0.17

Mother's schooling

$\leq 8$ years

1

$>8$ years

$0.99(0.60-1.64)$

0.98

Father's schooling

$\leq 8$ years

1

$>8$ years

$0.48(0.29-0.80)$

0.004

Household monthly income

(continuous variable)

1.0(0.9-1.0)

0.17

$\dagger$

Oral health conditions

Untreated dental caries lesions

No

1

Yes

$4.48(3.12-6.44)$

$<0.001$

$3.35(2.26-4.97)$

$<0.0001$

GI

Mild

1

Moderate

$1.89(1.09-3.26)$

$\dagger$

Severe

$2.69(1.61-4.51)$

0.02

0.001

$\mathrm{OHI}-\mathrm{S}$

Excellent

1

Good

1.28(0.57-2.87)

0.55

$3.41(1.58-7.37)$

0.002

Moderate

$3.69(1.76-7.70)$

0.001

ooth discoloration

No

1

Yes

$3.65(2.11-6.32)$

1

DDE Index-extension

Normal

\section{1}

$<1 / 3$

$0.88(0.50-1.57)$

0.67

$\dagger$

$\geq 1 / 3<2 / 3$

$2.41(1.36-4.27)$

0.003

Dried lips

No

Yes

$1.27(0.70-2.31)$

0.43

Continue... 


\begin{tabular}{|c|c|c|c|}
\hline \multicolumn{4}{|c|}{ Continuation } \\
\hline \multicolumn{4}{|c|}{ Fissured lips } \\
\hline No & 1 & & $\dagger$ \\
\hline Yes & $1.35(0.74-2.44)$ & 0.32 & \\
\hline \multicolumn{4}{|c|}{ Swollen lips } \\
\hline No & 1 & & $\dagger$ \\
\hline Yes & 1.00 (0.55-1.82) & 0.98 & \\
\hline
\end{tabular}

p* Calculated by Wald Test; RR: Rate Ratio; †: Covariate not significant; GI: Gingival Index; OHI-S: Simplified Oral Hygiene Index; DDE: Developmental defects of enamel.

It is known that the normal color of the primary teeth is lighter and whiter than that of the permanent teeth. Teeth become darker with age as a physiological change which could be due to the deposition of secondary dentine, wear of enamel, or extrinsic discoloration. ${ }^{24} \mathrm{On}$ the other hand, the tooth discoloration in individuals with liver disease is related to the amount of pigment deposition, which is proportional to the total serum bilirubin. Thus, the extent and intensity of the pigmentation could be directly related to the duration and severity of the liver disease. ${ }^{30,31}$

All children included in this study were from the Brazilian Northeast region. They were referred to the AC Camargo Cancer Center; Sao Paulo (Brazilian Southeast region) to continue their medical treatment. As such, data on their initial serum bilirubin levels could not be obtained. Information about the initial neonatal serum bilirubin concentration and data on hyperbilirubinemia could not be also obtained. It was therefore not possible to associate the presence of the diverse tones of tooth discoloration to the duration and severity of the liver diseases in our participants. Nonetheless, we believe that these limitations could not alter the study findings, since the study design (cross-sectional) does not enable the determination of causality, and because it was not the objective of this research.

On the other hand, it has been reported that parents feel responsible when their children exhibit oral health alterations at an early age hence the feeling of guilty could increase with the severity of the alteration. ${ }^{32,33}$ It must be emphasized that only children's mothers answered the quality of life questionnaire (B-ECOHIS). This could be explained by the fact that children had to move to another region to continue their treatment, and most of them moved only with their mothers.
In this study, tooth discoloration had a negative impact on the children's OHRQoL since mothers might be concerned about their children's health. Then, the aesthetic compromise of stained teeth could cause anxiety in children's mothers that could result in them expressing feelings of guilt or being emotionally disturbed when their children had these health problems. ${ }^{34}$ This is an important issue since the daily lives of children who are candidates for liver transplantation could present many challenges for them and their families. ${ }^{35}$

Although in this research a negative impact on the children's OHRQoL due to tooth discoloration and untreated dental caries was observed, it has been reported that children with liver diseases may also present other oral alterations such as developmental enamel dental defects. Regarding these alterations, they may arise due to changes in the organic matrix of the developing enamel resulting from metabolic disturbances. ${ }^{6}$ Other studies showed that these alterations could be related to the effects of osteopenia and disorders of calcium/phosphate metabolism that occur during chronic liver diseases. ${ }^{4,30}$ In this study, DDE such as opacities and hypoplasia were observed at a lower rate and did not show any negative impact on the children's OHRQoL. ${ }^{10}$

This study has the limitations of a typical cross-sectional study; hence, it was not possible to determine causal relationships between the variables. The convenience sample also limited the results which cannot be extrapolated to the entire population of pediatric patients with liver disease. For this reason, further studies are needed to provide more information about oral health conditions and to assess their impact on the OHRQoL of children with systemic diseases. A few cross-sectional studies 
have evaluated the impact of oral conditions on the OHRQoL of children with systemic diseases, ${ }^{13-15}$ although only one study was conducted in preschool children. ${ }^{15}$ Most of these studies have demonstrated that children's OHRQoL was negatively affected by oral conditions, mainly dental caries. This is in accordance with our results. However, there is still a clear knowledge gap concerning oral health and its impact on the OHRQoL of children with systemic diseases.

Above all, our findings highlight the importance of oral health promotion in early life, especially in children with systemic diseases, and the understanding of the relationship between general health and oral health. Children with systemic diseases and/or children on a liver transplantation waiting list exhibit oral health alterations that demand a dentist's attention as a priority. Thus, oral clinical examinations could enhance oral health and control oral diseases before liver transplantation. We believe that more efforts and resources need to be directed toward education and clinical care, which would culminate in an enhanced quality of life for children with systemic diseases.

\section{Conclusion}

In the present study, tooth discoloration and untreated caries lesions have a negative impact on the OHRQoL in a sample of pediatric liver transplant candidates.

\section{Acknowledgments}

The authors wish to thank Conselho Nacional de Desenvolvimento Científico e Tecnológico (CNPq processo 141118/2013-0) for funding support. Also, the authors would like to thank all the mothers and children for their cooperation.

\section{References}

1. Sokol RJ. Introduction to the pediatric liver research agenda: a blueprint for the future. J Pediatr Gastroenterol Nutr. 2002;35(1 Suppl 1):S2-3. https://doi.org/10.1097/00005176-200207001-00002

2. Spada M, Riva S, Maggiore G, Cintorino D, Gridelli B. Pediatric liver transplantation. World J Gastroenterol. 2009 Feb;15(6):648-74. https://doi.org/10.3748/wig.15.648

3. Belanger GK, Sanger DD, Casamassimo PS, Bystrom MS. Oral and systemic findings in biliary atresia: report of 11 cases. Pediatr Dent. 1982;4(4):322-6.

4. Morisaki I, Abe K, Tong LS, Kato K, Sobue S. Dental findings of children with biliary atresia: report of seven cases. ASDC J Dent Child. 1990 May-Jun;57(3):220-3.

5. Seow WK, Shepherd RW, Ong TH. Oral changes associated with end-stage liver disease and liver transplantation: implications for dental management. ASDC J Dent Child. 1991 Nov-Dec;58(6):474-80.

6. Amaral TH, Guerra CS, Bombonato-Prado KF, Silva FWGP, Queiroz AM. Tooth pigmentation caused by bilirubin: a case report and histological evaluation. Spec Care Dentist. 2008 Nov-Dec;28(6):254-7. https://doi.org/10.1111/j.1754-4505.2008.00048.x

7. Carrillo A, Rezende KM, Carrillo SR, Arana-Chavez VE, Bönecker M. Hyperbilirubinemia and intrinsic pigmentation in primary teeth: a case report and histological findings. Pediatr Dev Pathol. 2011 Mar-Apr;14(2):155-6. https://doi.org/10.2350/10-10-0929-LET.1

8. McGrath C, Broder H, Wilson-Genderson M. Assessing the impact of oral health on the life quality of children: implications for research and practice. Community Dent Oral Epidemiol. 2004 Apr;32(2):81-5. https://doi.org/10.1111/i.1600-0528.2004.00149.x

9. Locker D, Allen F. What do measures of 'oral health-related quality of life' measure? Community Dent Oral Epidemiol. 2007 Dec;35(6):401-11. https://doi.org/10.1111/j.1600-0528.2007.00418.x

10. Corrêa-Faria P, Paixão-Gonçalves S, Paiva SM, Martins-Júnior PA, Vieira-Andrade RG, Marques LS, et al. Dental caries, but not malocclusion or developmental defects, negatively impacts preschoolers' quality of life. Int J Paediatr Dent. 2016 May;26(3):211-9. https://doi.org/10.1111/ipd.12190

11. Martins-Júnior PA, Vieira-Andrade RG, Corrêa-Faria P, Oliveira-Ferreira F, Marques LS, Ramos-Jorge ML. Impact of early childhood caries on the oral health-related quality of life of preschool children and their parents. Caries Res. 2013;47(3):211-8. https://doi.org/10.1159/000345534

12. Borges TS, Vargas-Ferreira F, Kramer PF, Feldens CA. Impact of traumatic dental injuries on oral health-related quality of life of preschool children: a systematic review and meta-analysis. PLoS One. 2017 Feb;12(2):e0172235. https://doi.org/10.1371/journal.pone.0172235 
13. Abanto J, Ortega AO, Raggio DP, Bönecker M, Mendes FM, Ciamponi AL. Impact of oral diseases and disorders on oral-health-related quality of life of children with cerebral palsy. Spec Care Dentist. 2014 Mar-Apr;34(2):56-63. https://doi.org/10.1111/scd.12028

14. Wogelius P, Rosthøi S, Dahllöf G, Poulsen S. Oral health-related quality of life among survivors of childhood cancer. Int J Paediatr Dent. 2011 Nov;21(6):465-7. https://doi.org/10.1111/i.1365-263X.2011.01134.x

15. Buczynski AK, Castro GF, Leão AT, Souza IP. Impact of oral health on the quality of life of 3-6-years old HIV-infected children. Quality of life in HIV+ children. Eur J Paediatr Dent. 2011 Jun;12(2):81-6.

16. Tesch FC, Oliveira BH, Leão A. [Semantic equivalence of the Brazilian version of the Early Childhood Oral Health Impact Scale]. Cad Saude Publica. 2008 Aug;24(8):1897-909. Português. https://doi.org/10.1590/S0102-311X2008000800018

17. Scarpelli AC, Oliveira BH, Tesch FC, Leão AT, Pordeus IA, Paiva SM. Psychometric properties of the Brazilian version of the Early Childhood Oral Health Impact Scale (B-ECOHIS). BMC Oral Health. 2011 Jun;11(19):19. https://doi.org/10.1186/1472-6831-11-19

18. Martins-Júnior PA, Ramos-Jorge J, Paiva SM, Marques LS, Ramos-Jorge ML. Validations of the Brazilian version of the Early Childhood Oral Health Impact Scale (ECOHIS). Cad Saude Publica. 2012 Feb;28(2):367-74. https://doi.org/10.1590/S0102-311X2012000200015

19. Silness J, Löe H. Periodontal disease in pregnancy. 3. Response to local treatment. Acta Odontol Scand. 1966 Dec;24(6):747-59. https://doi.org/10.3109/00016356609028739

20. Greene JC, Vermillion JR. The simplified oral hygiene index. J Am Dent Assoc. 1964 Jan;68(1):7-13. https://doi.org/10.14219/jada.archive.1964.0034

21. World Health Organization - WHO. Oral health surveys: basic methods. Geneva: World Health Organization; 2013.

22. FDI. A review of developmental defects of enamel index (DDE index). Commission on Oral Health, Research \& Epidemiology. Report of an FDI Working Group. Int Dent J. 1992 Dec;42(6):411-26.

23. Gomes MC, Pinto-Sarmento TC, Costa EM, Martins CC, Granville-Garcia AF, Paiva SM. Impact of oral health conditions on the quality of life of preschool children and their families: a cross-sectional study. Health Qual Life Outcomes. 2014 Apr;12(55):55. https://doi.org/10.1186/1477-7525-12-55

24. Watts A, Addy M. Tooth discoloration and staining: a review of the literature. Br Dent J 2001; 190(6), 309-316. htpps://doi:10.1038/sj.bdj.4800959a.

25. Ministério da Saúde (BR). Projeto SB Brasil 2010: Pesquisa Nacional de Saúde: resultados principais. Brasília, DF: Ministério da Saúde; 2010.

26. Kassebaum NJ, Bernabé E, Dahiya M, Bhandari B, Murray CJ, Marcenes W. Global burden of untreated caries: a systematic review and metaregression. J Dent Res. 2015 May;94(5):650-8. https://doi.org/10.1177/0022034515573272

27. Ramos-Jorge J, Pordeus IA, Ramos-Jorge ML, Marques LS, Paiva SM. Impact of untreated dental caries on quality of life of preschool children: different stages and activity. Community Dent Oral Epidemiol. 2014 Aug;42(4):311-22. https://doi.org/10.1111/cdoe.12086

28. Ramos-Jorge J, Sá-Pinto AC, Almeida Pordeus I, Paiva SM, Martins CC, Ramos-Jorge ML. Effect of dark discolouration and enamel/dentine fracture on the oral health-related quality of life of pre-schoolers. Eur Arch Paediatr Dent. 2017 Apr;18(2):83-9. https://doi.org/10.1007/s40368-017-0271-2

29. Carvalho E, Santos JL, Silveira TR, Kieling CO, Silva LR, Porta G, et al. Biliary atresia: the Brazilian experience. J Pediatr (Rio J). 2010 Nov-Dec;86(6):473-9. https://doi.org/10.1590/S0021-75572010000600005

30. Guimarães LP, Silva TA. Green teeth associated with cholestasis caused by sepsis: a case report and review of the literature. Oral Surg Oral Med Oral Pathol Oral Radiol Endod. 2003 Apr;95(4):446-51. https://doi.org/10.1067/moe.2003.43

31. Alto LA, Pomarico L, Souza IP, Janini ME. Green pigmentation of deciduous teeth: report of two cases. J Dent Child (Chic). 2004 MayAug;71(2):179-82.

32. Carvalho TS, Abanto J, Mendes FM, Raggio DP, Bönecker M. Association between parental guilt and oral health problems in preschool children. Braz Oral Res. 2012 Nov-Dec;26(6):557-63. https://doi.org/10.1590/S1806-83242012000600012

33. Carvalho TS, Abanto J, Pinheiro EC, Lussi A, Bönecker M. Early childhood caries and psychological perceptions on child's oral health increase the feeling of guilt in parents: an epidemiological survey. Int J Paediatr Dent. 2018 Jan;28(1):23-32. https://doi.org/10.1111/ipd.12306

34. Goettems ML, Ardenghi TM, Romano AR, Demarco FF, Torriani DD. Influence of maternal dental anxiety on oral health-related quality of life of preschool children. Qual Life Res. 2011 Aug;20(6):951-9. https://doi.org/10.1007/s11136-010-9816-0

35. Sahin $Y$, Virit $O$, Demir B. Depression and anxiety of children who are candidates for liver transplantation. Arq Gastroenterol. 2016 Jan-Mar;53(1):25-30. https://doi.org/10.1590/S0004-28032016000100006 